\title{
A Survey Based Study of Strategic Directions of Saudi Universities Aligned with Economic Development Supporting Vision of 2030
}

\author{
Faten Dhawi ${ }^{1}$, Talal Albaqami ${ }^{2}$ \\ ${ }^{1}$ Biotechnology Department, King Faisal University, Al-Hofuf, KSA \\ ${ }^{2}$ College of Business, Clayton State University, Morrow, USA \\ Email:dr.faten.dhawi@gmail.com,falmuhanna@kfu.edu.sa,dr.talal.albaqami@gmail.com
}

How to cite this paper: Dhawi, F. and Albaqami, T. (2017) A Survey Based Study of Strategic Directions of Saudi Universities Aligned with Economic Development Supporting Vision of 2030. Journal of Human Resource and Sustainability Studies, 5, 167-178.

https://doi.org/10.4236/jhrss.2017.53016

Received: August 17, 2017

Accepted: September 19, 2017

Published: September 22, 2017

Copyright $\odot 2017$ by authors and Scientific Research Publishing Inc. This work is licensed under the Creative Commons Attribution International License (CC BY 4.0).

http://creativecommons.org/licenses/by/4.0/

c) (i) Open Access

\begin{abstract}
The role of universities is centered on education and qualification to raise the level of science and awareness in society. Considering the global economic changes, it is necessary to prepare universities to raise their level of physical in parallel with raising the academic and research level. In the current research, we conducted an electronic questionnaire targeting a random group of young men and women, the majority of whom were in the age group 20 to 35 years old. Responses ranged from strong approval to support and even total rejection of the use of paid services provided by the university, but the vast majority approved strongly. It was also found that most of the random sample concerned by the quality of the services provided by the university from workshops, courses and exhibitions to serve the rehabilitation of the labor. In addition, documentation of the attendance with a certificate was highly demanded. The results also indicated a general acceptance to pay $5 \%$ of the value of the profits of sales in case of presentation at the university and the nomination of the best price for the short courses of the university ranged from $100-200$ Saudi Riyals (SAR). Therefore, the study shows a general acceptance of the concept of paid services because of the system of the free educational systems in Saudi Arabia, which makes the availability of short courses and workshops at an acceptable price is welcomed. Strengthening the financial resources of Saudi universities is a challenge that can be overcome while ensuring community cooperation and greater transparency. The means of strengthening financial resources can be limited using two methods. First, provide a variety of services at competitive prices. Second, reduce financial waste resulting from energy misuse of learning resources, such as chemicals, operating plants and devices, by linking the different faculties at the university to a single database. The data base will ensure to enable users of academics, researchers and grad-
\end{abstract}


uate students to screen resources availability and avoid duplication of requests in case of adequate coverage.

\section{Keywords}

Vision 2030, Universities, Saudi Arabia, Finance, Budget, Human, Resources, Management

\section{Introduction}

Countries worldwide in the globe are moving towards raising their economies in several ways. Saudi Arabia is no exception considering the economic transition towards a productive country and a promising investment center. The Cabinet approved the "Vision 2030" plan on April 25, 2016, presented by His Royal Highness and Chairman of the Council for Economic Affairs and Development Prince Mohammed Bin Salman Al Saud. This vision aims to raise the profile of the Kingdom of Saudi Arabia to the forefront of public investments in global investment funds. There is no doubt that education is the center of scientific and knowledge investment and therefore the Ministry of Finance has put at least 80 billion Saudi Riyals (SAR) for the education, training and manpower sector. In a statistical study on the extent of expending in Saudi universities, which was prepared by the Ministry of Education, the results revealed that most of the university expenditure and $55.6 \%$ are spent as salaries and allowances while the remainder of the budget is spent on other expenses. Therefore, the Saudi universities are in front of an economic objective and a national duty to keep pace with the global change in sources of funding. National transformation, economic changes in Saudi Arabia and the global economic trend impose an additional role on Saudi universities not only in management and marketing, but in re-shaping the role of universities in scientific research and community partnership. Not to mention the most important role in the graduation of human competencies, which can contribute to raising the national economy and community development. To the best of our knowledge this is the first study considering public view following the vision of 2030.

As announced by official Saudi Arabia's 2017 Fiscal Budget, annual expenditure is spent on education and health care reached $32 \%$. On the hand, spending on military and security services constitutes the largest single share at $32 \%$. The aim of this research is to study ways of enhancing the financial resources of Saudi universities in line with the vision of 2030 and the extent to which community members respond to the use of the services provided by the university to support its budget. To achieve this research, a short survey was conducted to measure the extent to which the society accepted the idea of paid services in universities and the acceptable price in most sectors of society. In this article, we described the method used then show results with graphs. Followed by discussion and authors insight and ideas based on public view of the current economic status. We dis- 
cussed two main issues related to the current economic status. First approach, proposals and recommendations to strengthen the financial resources of Saudi universities through diversification of sources of intervention. Second approach, strengthening the financial resources by stopping waste due to misuse of resources and delays in maintenance. The article followed by the full questionnaire in appendix section.

\section{Methods}

A 14-question questionnaire was used to measure the acceptability of the services provided by the universities for a fee and the amount accepted in this case. The study included a random sample of males and females at various stages ranging from university students to employees in various sectors and age group from 20 years to 35 years and above. The workshops included: workshops, short courses, academic consultations provided by faculty members and exhibitions of productive families with a fee of $5 \%$ of the total sales, as well as the type of services that may be provided to researchers and employers. Respondents' responses were measured as strongly agreed, agreed, maybe, disagree and strongly disagree. The results of the electronic questionnaire, which included 270 responses were collected and analyzed using SPSS to confirm the normal distribution of the sample [1].

\section{Results}

Social and economic development may meet under the edifice of education if educational plans have been adapted to achieve that goal. In the current study, the results were promising among the large acceptance of the sample to pay fees for some services provided by the universities. The data for the questionnaire were collected 15 days after the establishment of the questionnaire and a response was recorded to 270 individuals, $51 \%$ of whom were males compared to $49 \%$ of females. The highest percentage of the sample was recorded in the age group 25 - 35 years by more than $40 \%$, followed by the age group was 20 - 25 years by more than $30 \%$ (Figure $1(\mathrm{a})$ ). The percentage of university students in the sample was $55 \%$, followed by $21 \%$ of non-students (Figure $1(\mathrm{~b})$ ). The percentage of those who wish to display their own craft or talent is more than $80 \%$ of the sample, with a $35 \%$ probability and a strong approval of $25 \%$ (Figure $2(\mathrm{a})$ ). Accordingly, the percentage of those wishing to pay $5 \%$ of their sales profits showed in the university exceeded $70 \%$ (Figure $2(\mathrm{~b})$ ). In terms of paid courses, which could be offered by the university, the percentage of those wishing to attend courses matched work preparation or their qualification or future specialization was more than $90 \%$ with a strongly agreed majority of $33 \%$ (Figure 3(a), Figure 3(b)). The presence of paid services provided by the faculty members, such as technical and academic consultations, was less popular than the sample's response to the previous questions, but is still high for the sample size significantly more than $55 \%$ (Figure $4(\mathrm{a})$ ). As an inevitable result of this 
(a) Age range

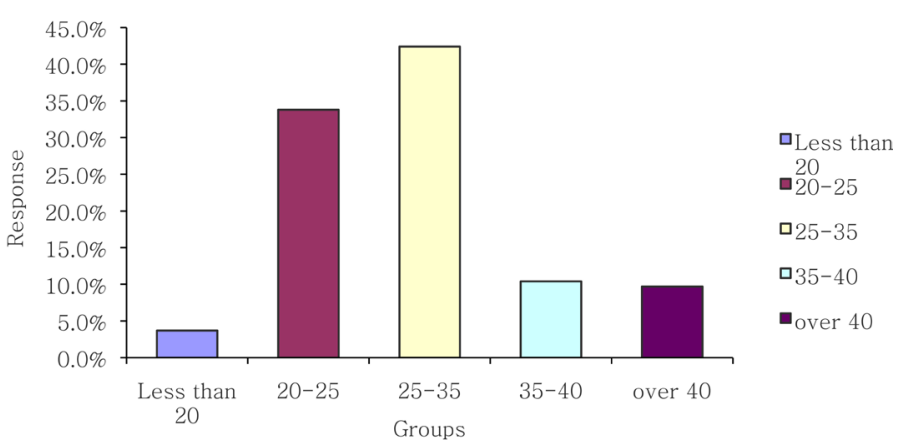

(b)

Current status

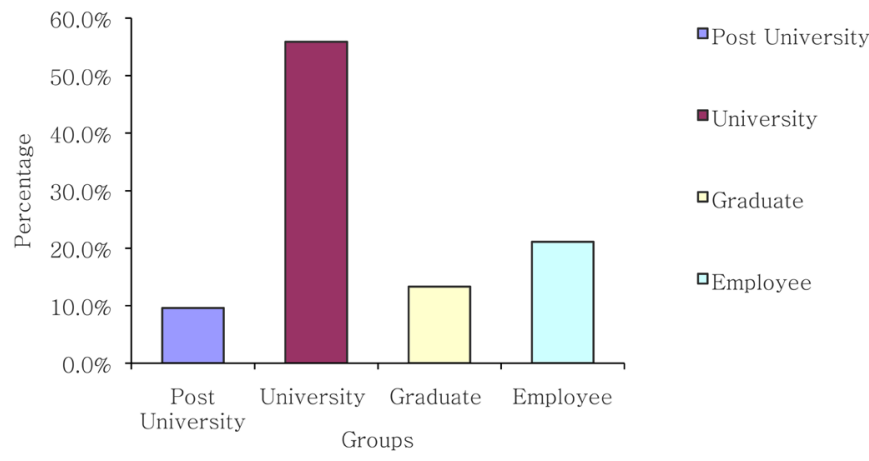

Figure 1. (a) The randomized study sample included different age stages, most of them greater than 25; (b) the current state of the study sample.

(a) If you have a talent or craft, would you like to participate at

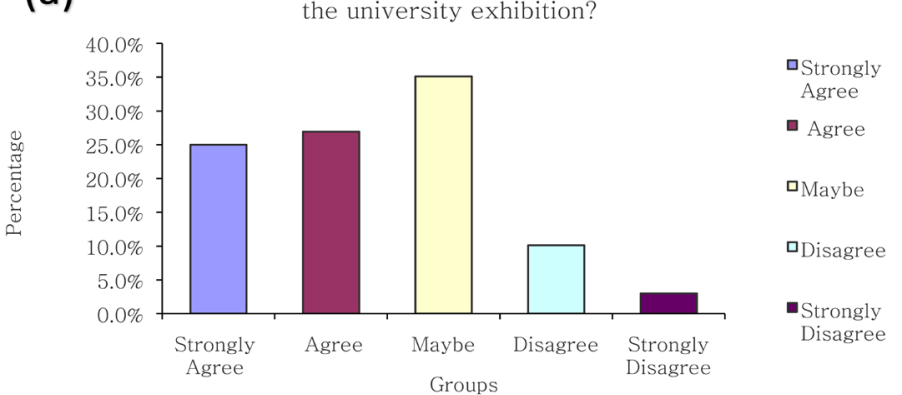

(b) How much do you agree to take $5 \%$ of your sales when you

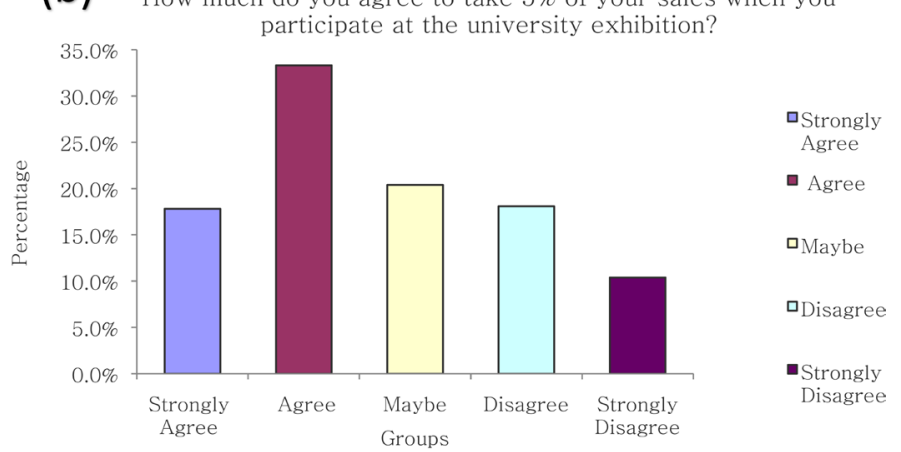

Figure 2. (a) Percentage of sample response to gifted or craftsmen support program; (b) percentage of respondents' response to $5 \%$ of their sales when they are offered at the university. 
(a) If there is a workshop prepared by the university in your field of specialization or numbers for the job, will you be keen to attend

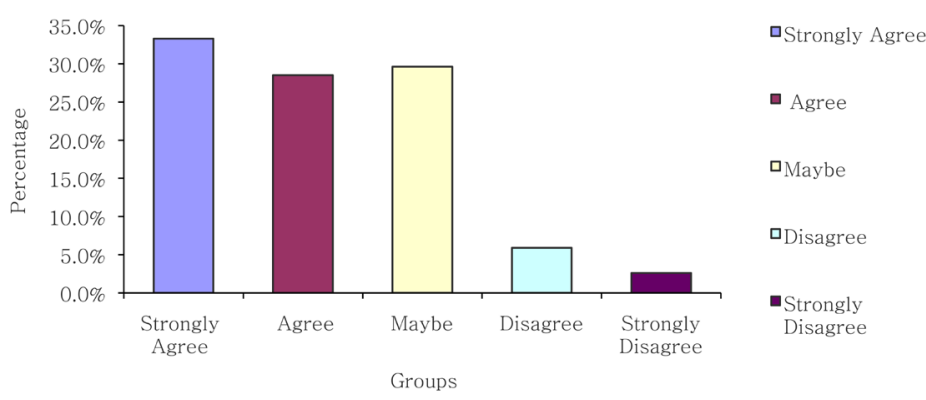

(b) If you have a workshop or a course in the field of your interest, will you be keen to attend?
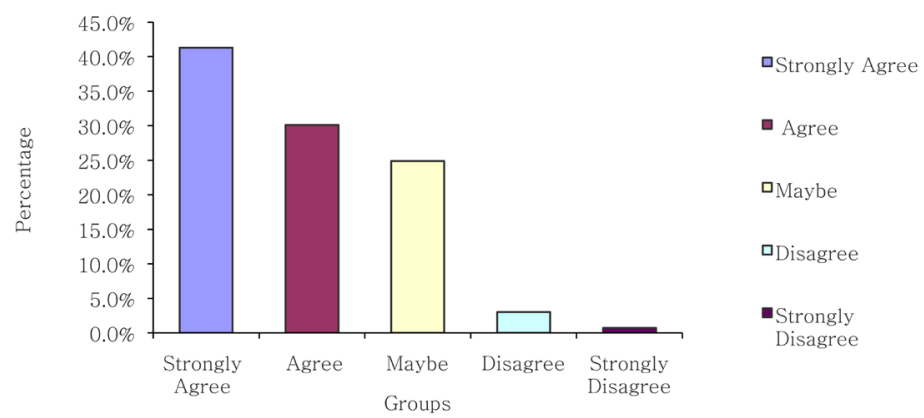

Figure 3. (a) Percentage of the sample's desire to attend a workshop related to the job preparation; (b) the percentage of the sample's response to the presence of courses in different technical fields or hobbies.

(a) How much do you use for paid services provided by faculty

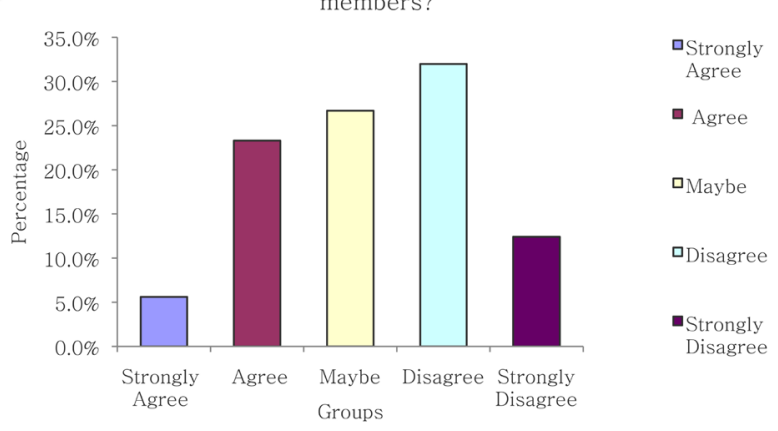

(b) What is the most challenging scientific researcher may face?

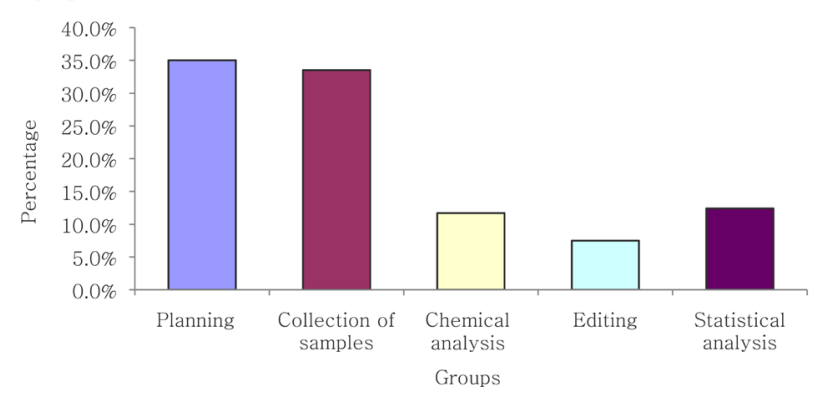

Figure 4. (a) The extent to which the sample of the study responded to the services paid by the faculty members; (b) the extent to which the sample of the study responded to the difficulties encountered in the research. 
(a) The most influential factor to attend a course or workshop at the university is to have a certificate approve the attendance of the course

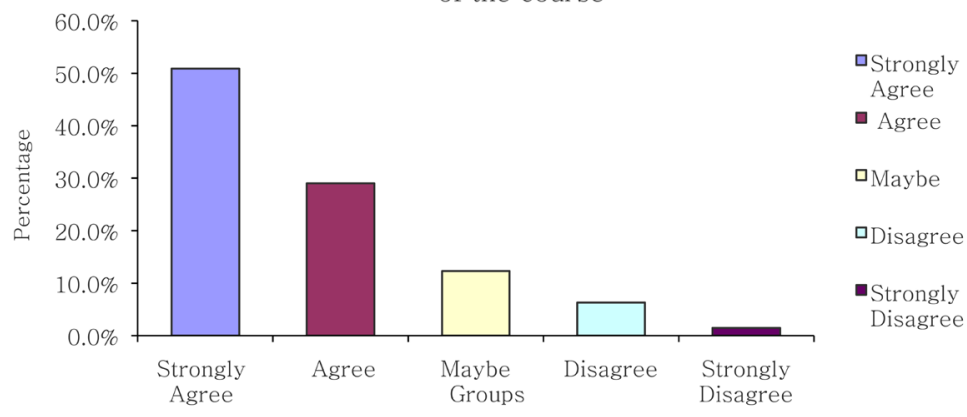

(b) The most influential factor to attend a course or workshop at the

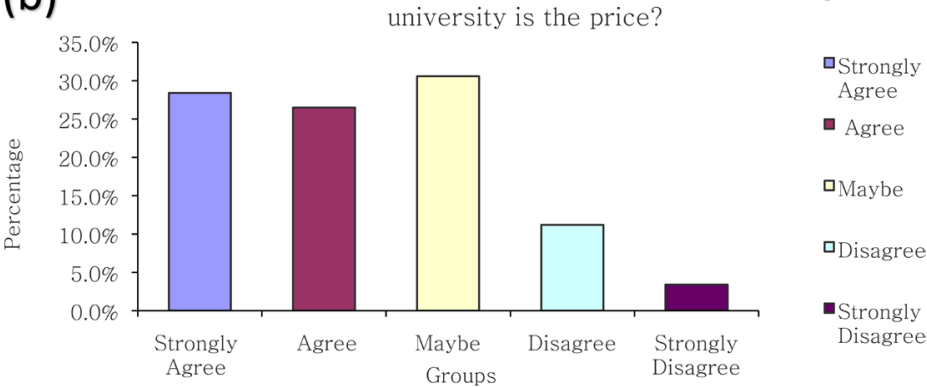
(c) The most influential factor to attend a session or workshop at the
university is the timing

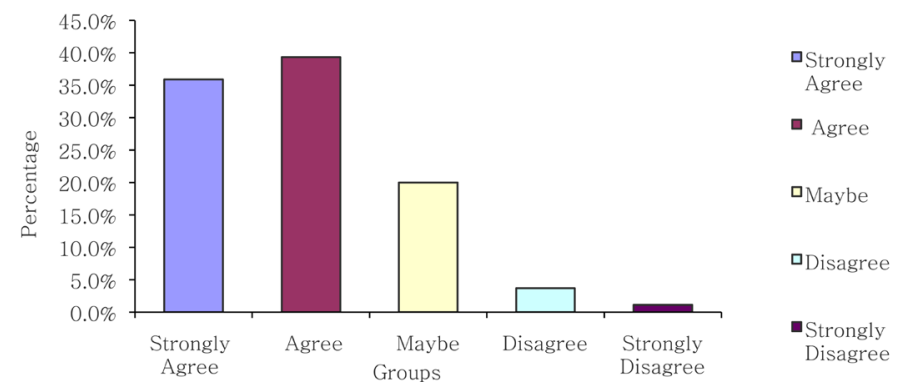

Figure 5. (a)-(c) Sample response on the impact of various factors such as the price or timing of the session or the existence of a certificate of attendance.

question, a question was added that serves the category of students of scientific research and postgraduate studies in the type of counseling or potential services that can be provided by faculty members. The research planning stage recorded the highest percentage (35\%) followed by $33 \%$ sample collection (Figure 4(b)). The percentage of voting for the most influential factor to attend a university session was $95 \%$, followed by a certificate of attendance of more than $92 \%$, followed by the value of the course or the offered price by $85 \%$ (Figures $5(\mathrm{a})-(\mathrm{c})$ ). The acceptable fees for the courses or workshops provided by the university from the point of view of the sample included in the study ranged from 100 - 200 SAR with a strong approval of more than $37 \%$, followed by $20 \%$ for fees ranging from 200 - 300 SAR. From 300 to 500 SAR by 14\% (Figure 6(a)). For the purchase of souvenirs with the university logo, the approval rate was more than $20 \%$ with a general support of $64 \%$ (Figure 6(b)). 


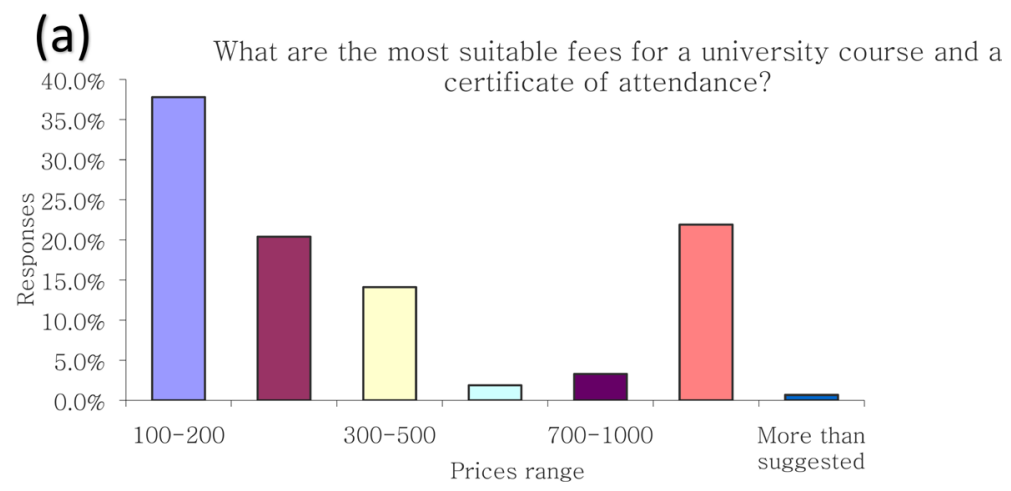

(b) If there is a souvenir shop with a university logo, would you like to buy?

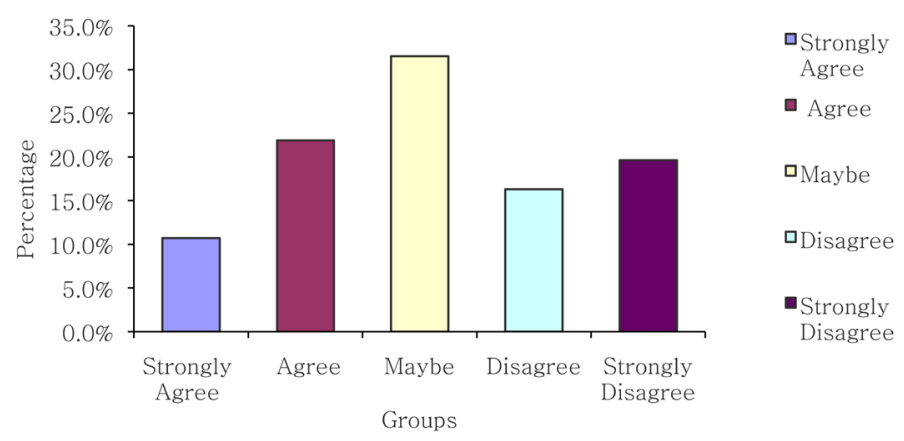

Figure 6. (a) The extent to which the sample of the study responded to the price of the courses or workshops offered by the university; (b) the extent to which the sample of the study responded to the desire to purchase souvenir products bearing the university logo.

\section{Discussion}

The change in the free economy imposes on universities an additional role in changing their strategy not only at the administrative and educational level, but also in supporting community partnership and the graduation of qualified human power for this change [2]. Therefore, Saudi Arabia, considering the global economic changes, is seeking to support the local economy and to find financial resources for the promotion of self-resources and universities is no exception to this trend. In 1428, the Ministry of Education increased its financial resources by organizing several bodies including the Ministry of Finance, the Ministry of Economy and Planning, the Ministry of Education, the Supreme Economic Council and the Council of Chambers of Commerce on 22/7/1428H, and school vending and transportation [3]. The expansion of the investment rules provides capital to expand the activity of any institution and increases the probability of increasing income from various sources [4]. A good example of this was the 2030 vision presented by His Royal Highness Prince Mohammed bin Salman Al Saud, seeking to transform Saudi Arabia into productive country with a stable local economy. Therefore, it was necessary to direct the universities towards an administrative, technical and financial organization to achieve cooperation between the labor market and educational institutions [5]. This study has led to several recommendations to strengthen financial resources, stop waste, save 
university resources and ideas to diversify sources of income considering the questionnaire and recorded response of a random sample of members of society with the subject of the study.

\subsection{Proposals and Recommendations to Strengthen the Financial Resources of Saudi Universities through Diversification of Sources of Intervention}

\subsubsection{Strengthen Resources by Providing Extracurricular Learning Paths}

The results indicate the importance of diversifying sources of income to suit all segments of the society, including young consumers under the age of 20 and 25, as well as the group with the largest cash flow in the age group of 35 years and above. Therefore, it was necessary for universities to be flexible in thinking, especially when dealing with groups of society less than 20 years and commensurate with the habits of society and under the supervision of specialists in terms of marketing sources that address this category and not without entertainment. The ability of the individual to spend between 200 riyals and less, according to the study, so consider the work of financial cycles reduced financial or social situations, so the provision of services desired according to the aspirations of the consumer or individual at a competitive price and higher quality to ensure consumer demand and increase income [6]. The establishment of short courses and workshops that serve job seekers at prices ranging from 100 to 300 riyals and certificates authenticated by the university under the supervision of qualified faculty members will contribute greatly to enhancing the university's resources. Providing academic consultations with nominal fees to the beneficiaries of the community members who wish to carry out a research study or cooperate with the educational sector. Provide work contracts for outstanding graduates to carry out workshops and training courses for students at nominal prices. At this point, two objectives are achieved: to provide jobs and support to the community and reduce the costs of training staff by providing qualified competencies. The establishment of an annual ceremony to invite former graduates and raise funds to support the university with the existence of an honorary club for donors and grant them some privileges to contributes significantly of raising economic of universities. An example of alumni privileges is free access to university clubs and organizations. Another example can be a conditional admission of one the alumni relatives to the university.

\subsubsection{Strengthen Financial Resources by Sponsoring Exhibitions and Productive Families}

The results indicated general approval and keen acceptance of the university care in the event of support exhibitions for the productive families with a simple rate of not more than $5 \%$ of the sales profits, thus supporting the community partnership and supporting financial resources. Thus, contributes of small business management and the achievement of community partnership and financial gains on the condition of efficient coordination and management of these exhibitions to attract the highest numbers of future employers. 


\subsubsection{Strengthen Resources by Supporting Scientific Research and Global Conferences}

There is no doubt that the scientific research movement as much as it drains financial resources, but it can be a financial source if it was well planned. Examples include the establishment of local seminars and international conferences that attract people interested in various scientific fields with registration fees to be included in the university budget. In addition, providing services to researchers in science in accordance with the results of the questionnaire, where most of the problems of researchers in the study sample and planning research. It is possible that the university will provide the service of creating an electronic questionnaire or hosting the service at an appropriate amount, especially in the research directed to the university students as a sample study or the youth group as a model study in the age of $18-25$ years. The results also indicated that there are problems faced by researchers in the analysis of chemical samples, which can be done by research laboratories of universities at competitive prices to conduct chemical analysis of individuals and researchers.

\subsubsection{Strengthening Resources by Providing Services and Educational Tourism}

Providing services such as health care in the work of a rapid diagnosis clinic under the Faculty of Medical Sciences or laboratories supervision, this include initially performs simple tests such as comprehensive blood analysis and identification of the species or lack of nutrition with an economic fee. Provide facilities with additional services for students such as barbershop in the male student sections and beauty salon in the female student sections at a competitive price. In addition, shops to rent cars or bicycles on the campus in an hourly fee. Achieve a recreational gain for students as well as a financial by supporting athletes from students and achieving championships for university team. In addition, to the possibility of achieving the educational arena by introducing the campus in the list of places that can provide educational tourism services by identifying its facilities and specialties by appointing an office of competent qualifications for this at special price. It is also possible to hand over student and hotel accommodation to hotels in tourist cities such as Taif, Abha and Al-Ahsa and to use part of the summer accommodation for those wishing to rent and to know the university and its facilities.

\subsection{Strengthening Financial Resources by Stopping Waste Due to Misuse of Resources and Delays in Maintenance}

1) The establishment of an electronic database that includes chemicals and their specifications and places of presence in all the faculties of the University and the allocation of incomes for technicians working in the university and faculty members only.

2) The establishment of database to include laboratory devices and tools that can be used in scientific research or teaching and the extent of their use and validity to facilitate the inventory of the existing and reduce the expenses resulting 
from the request of devices not used in another college labs.

\subsubsection{The Application of the Chemical Database and the Contents of the} College of Warehouse Management Will Have a Positive Effect on the Following Areas

- Reduce the waste of chemicals and the repeated purchase that happen accidently without checking with University stock.

- Improve the user's discharge from them in a way that does not harm public health and the environment.

- Expanding the base of academic and research cooperation among university faculties.

- Maintain security by monitoring chemical stocks and identifying their users.

- Determine the permanent need and predict future need for chemicals.

\subsubsection{As for the Contents of the University of Furniture and Equipment,} The Establishment of a Database Will Have a Positive Impact on

- Save the contents of the college from loss and mislabeling.

- Conversion of furniture or hardware from one beneficiary to another.

- In the case of dispensing or selling to other beneficiaries, this is recorded, which contributes to the save the university properties.

Both proposals can be applied to warehouse management and an electronic inventory is made to reduce waste resulting from the use of paper inventory and repeat work that can be electronically updated. Reducing cost by increasing efficiency achieves development priorities and reduces the amount of waste [7] [8].

Working with a database that contributes to improving and developing the work environment to promote academic work, strengthen financial resources and activate community partnership in the case of other entities that may benefit from the surplus resources of the university.

3) Periodic maintenance of the university facilities of water, electricity and communications increases the level of service quality and reduces the financial waste resulting from negligence, which may cost the value of establishing a new service.

\section{Conclusion}

The pursuit of the development and improvement of any educational system must be accompanied by the development of plans and strategies. Implanting different strategies for financial resources will make sure to keep pace with economic changes in the world. For the Saudi universities alignment with Vision 2030, it is necessary to strengthen the financial resources using two methods. The first is to diversify sources of income according to the recommendations mentioned in the current study. The second is to improve the level of services, which will stop wasting the resources from chemicals, equipment and facilities by linking them to a database that benefits all entities. The limitation of research considering wasted financial resources in each sector and utilizing a method to connect all government sectors for efficient management is one of the major 
challenges and recommended for further research.

\section{References}

[1] Green, S.B. and Salkind, N.J. (2010) Using SPSS for Windows and Macintosh: Analyzing and Understanding Data. Prentice Hall Press, Upper Saddle River.

[2] Sherbini, F. (2009) New Ways to Increase the Resources of Universities. Mayadeen Magazine, 18, 1430. (In Arabic Language)

[3] Al-Otaibi, B.M., Al-Babtain, A.M. and Al-Otaibi, M.E. (1430) An Exploratory Study in the Fields of Privatization from the Point of View of the Concerned Bodies in the Ministry of Education. Ministry of Education, Planning and Development Agency, Riyadh. (In Arabic Language)

[4] Gemayel, S. (1997) The New Globalization and the Biosphere of the Middle East Concepts of an Coming Age. Center for Strategic Studies, Research and Documentation, Beirut. (In Arabic Language)

[5] Al-Hurr, A.M. (2003) Education, Development and Renaissance. Publishing Company for Distribution and Publishing, Beirut.

[6] Al-Shkawi, A.A.(1423) Towards Better Performance in the Government Sector in Saudi Arabia, Seminar on the Future Vision of the Saudi Economy. Ministry of Planning, Riyadh.

[7] Al-Tuwaijri, M.I.A. (1995) Saudi Arabia's Experience in Privatization (Privatization) Methodology of Graduation, Participation and Integration. Symposium on Arab Experiences in Privatization, Riyadh, 1-5 July 1995. (In Arabic Language)

[8] Arab Bureau of Education for the Gulf States (2008) Education Development Project in Member States of the Arab Bureau of Education for the Gulf States, Arab Bureau of Education for the Gulf States, Riyadh, 1427-1428. (In Arabic Language) 


\section{Appendix}

1) Age range

Less than 20

$20-25$

$25-35$

$35-40$

over 40

2) Status

Post University University Graduate Employee

3) If you have a talent or craft, would you like to participate at the university exhibition?

Strongly Agree

Agree Maybe Disagree Strongly Disagree

4) How much do you agree to take $5 \%$ of your sales when you participate at the university exhibition?

Strongly Agree

Agree Maybe Disagree

Strongly Disagree

5) If there is a workshop prepared by the university in your field of specialization or numbers for the job, will you be keen to attend

Strongly Agree

Agree Maybe Disagree

Strongly Disagree

6) If you have a workshop or a course in the field of your interest, will you be keen to attend?

Strongly Agree Agree Maybe Disagree Strongly Disagree

7) How much do you use for paid services provided by faculty members? Strongly Agree Agree Maybe Disagree Strongly Disagree

8) What is the most challenging scientific researcher may face?

$\begin{array}{lll}\text { Planning } & \text { Collection of samples } & \text { Chemical Analysis } \\ \text { Editing } & \text { Statistical analysis } & \end{array}$

9) The most influential factor to attend a course or workshop at the university is to have a certificate approve the attendance of the course

Strongly Agree Agree Maybe Disagree Strongly Disagree

10) The most influential factor to attend a course or workshop at the university is the price?

Strongly Agree Agree Maybe Disagree Strongly Disagree

11) The most influential factor to attend a session or workshop at the university is the timing

Strongly Agree Agree Maybe Disagree Strongly Disagree

12) What are the most suitable fees for a university course and a certificate of attendance?

$100-200 \quad 200-300 \quad 300-500 \quad 500-700 \quad 700-1000$

Less than suggested More than suggested

13) If there is a souvenir shop with a university logo, would you like to buy?

Strongly Agree Agree Maybe Disagree Strongly Disagree 
Submit or recommend next manuscript to SCIRP and we will provide best service for you:

Accepting pre-submission inquiries through Email, Facebook, LinkedIn, Twitter, etc. A wide selection of journals (inclusive of 9 subjects, more than 200 journals)

Providing 24-hour high-quality service

User-friendly online submission system

Fair and swift peer-review system

Efficient typesetting and proofreading procedure

Display of the result of downloads and visits, as well as the number of cited articles Maximum dissemination of your research work

Submit your manuscript at: http://papersubmission.scirp.org/

Or contact jhrss@scirp.org 